\title{
Effect of Rolling Reduction and Temperature on the Oxide Scale of Hot Rolled Mild Steel Strip
}

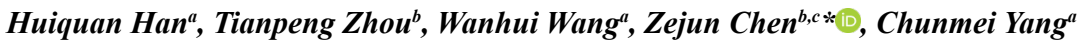 \\ ${ }^{a}$ CISDI Research \& Development Co., Ltd., Chongqing, 401122, China \\ ${ }^{b}$ College of Materials Science and Engineering, Chongqing University, Chongqing, 400044, China \\ 'State Key Laboratory of Mechanical Transmissions, Chongqing University, Chongqing, 400044, China
}

Received: January 30, 2019; Revised: July 30, 2019; Accepted: August 25, 2019

\begin{abstract}
Hot rolling experiments were designed to investigate the effect of rolling temperature and rolling deformation on microstructure, thickness and surface red scale of hot rolled mild steel oxide scale by spectrometer, SEM and pickling experiment. The research results show that in the same other experiment conditions, the greater the rolling deformation, the thinner the oxide scale extend; with the increase of rolling temperature, the plasticity of oxide scale is enhanced, the oxide scale can be compacted under a larger rolling reduction, which increase the adhesion of oxide scale to substrate and reduce the oxide scale falling off. The higher rolling temperature is, the greater the allowable critical deformation to inhibit red scale is, and the thicker tolerable thickness of the initial oxide scale is. In the process of hot strip rolling, improving rolling load distribution of the front frame and reducing the rolling deformation of the tail frame is helpful to control strip red scale and make oxide scale deform uniformly.
\end{abstract}

Keywords: oxide scale, hot rolling, steel strip, pickling.

\section{Introduction}

Because of the fierce market competition environment and the increasing restriction on environmental protection, the surface quality requirement of hot rolled pickled sheet is becoming more and more stringent. The thickness and characteristics of oxide scale of hot rolled mild steel sheet have important impacts on the following pickling and cold rolling process. Elimination of surface oxide scale residue, restraining of surface red scale, reduction of oxide scale thickness, improvement of pickling efficiency, which all means are taken with the purpose of improving the surface quality of hot rolled pickled sheet. Some reports show, alloy element ${ }^{1-3}$ properly reducing the content of $\mathrm{Si}^{3-7}$, appropriately increasing descaling temperature ${ }^{5,8}$, improving descaling system pressure ${ }^{8,9}$, eliminating roll surface falling off $^{9-12}$, etc. which are advantage of controlling oxide scale residue and red scale of sheet surface. However, the common oxide scale defects cannot be resolved well by only above measures due to the comprehensive influence referring to continuous cast, reheating $^{13}$, rolling and cooling ${ }^{14-18}$, etc. The aim of this research is to investigate the effect of rolling reduction and rolling temperature on oxide scales of mild steel. The research results are helpful in resolving and controlling the oxide scales of hot rolled steel production.

\section{Experimental Material and Procedure}

\subsection{Experimental material}

The chemical compositions of experimental steel are shown in Table 1 . The hot rolling samples were cut into $50 \mathrm{~mm} \times 40 \mathrm{~mm} \times 11.3 \mathrm{~mm}$.

Table 1. Chemical compositions of experimental steel (wt.\%)

\begin{tabular}{cccccc}
\hline $\mathbf{C}$ & $\mathbf{S i}$ & $\mathbf{M n}$ & $\mathbf{P}$ & $\mathbf{S}$ & $\mathbf{F e}$ \\
\hline 0.14 & 0.28 & 0.48 & 0.014 & 0.008 & balance \\
\hline
\end{tabular}

\subsection{Experimental process}

\subsubsection{Oxide scales preparation}

The aim of study is to investigate the effect of rolling parameters on the oxide scales of steel strip. The premise behind this study is to preparation the certain thickness of oxide scales on the surface of steel strip samples. The sketch diagram of the oxide scales preparation is shown in Fig. 1. The detailed steps are specified as follows:

Step 1: Take the cut steel strip sample, polish the surface to remove the oxide scales, and then keep it dry in the vacuum drying vessel before next step. 

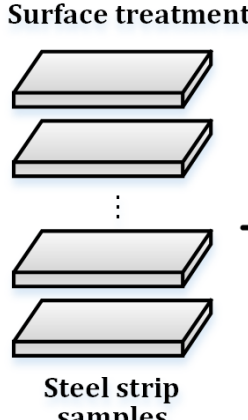

samples
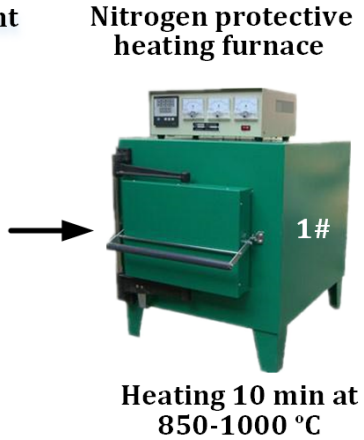

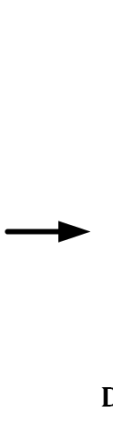

Air atmosphere heating furnace

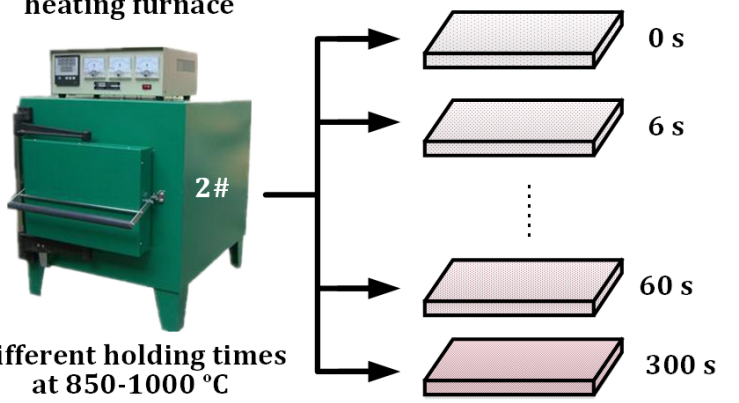

Figure 1. Sketch diagram of the oxide scales preparation.

Step 2: Switch on the power of heating furnace $1 \#$ and $2 \#$, heating up to the $850-1000^{\circ} \mathrm{C}$. The difference of heating furnace $1 \#$ and $2 \#$ is the ambient atmosphere of heating. The heating furnace $1 \#$ was heated at nitrogen $\left(\mathrm{N}_{2}\right)$ atmosphere, while the heating furnace $2 \#$ was at air atmosphere.

Step 3: Take the polished steel strip sample from the vacuum drying vessel into the furnace $1 \#$, holding $10 \mathrm{~min}$, and take it into furnace $2 \#$ rapidly, holding in different times (0 s-300 s). The oxide scales with different thickness can be obtained on the steel strip sample surface. The thickness of oxide scales of steel strip is mainly depending on its holding times in furnace $2 \#$.

Step 4: In order to measure the thickness of oxide scales at high temperature, the glass powder ${ }^{19}$ be immediately sprayed evenly on the surface of hot steel strip sample after it be take out from furnace $2 \#$. The thickness of oxide scales at high temperature was retained because the melted glass powders on the surface of steel strip prevent exposure to the outside air, and avoid the further oxidation. The steel strip samples were cooled to room temperature under the protection of melted glass powder.

Step 5: Cut the sample in the glass coating, and measure the thickness of oxide scales by SEM (Scanning Electron Microscope).

Based on above-mentioned experimental process, the thicknesses of oxide scales in different heat processes can be obtained, and be shown in Fig. 2. It can be seen that the thickness of oxide scales of steel strip sample increase with the increase of the oxidizing time and heating temperature.

\subsubsection{Rolling experiment}

The experimental procedures are as follows:

Step I: In order to investigate the effect of rolling temperature, the rolling experiments were carried out at different temperatures, $850{ }^{\circ} \mathrm{C}, 900{ }^{\circ} \mathrm{C}, 950{ }^{\circ} \mathrm{C}, 1000{ }^{\circ} \mathrm{C}$. The two different thick oxide scales need be prepared at each experimental temperature. One thick oxide scales promotes red scale and the anther inhibits red scale ${ }^{20}$. The initial oxide scales can be obtained by repeating the Step 1 and Step 3. The thickness oxide scales can be determined

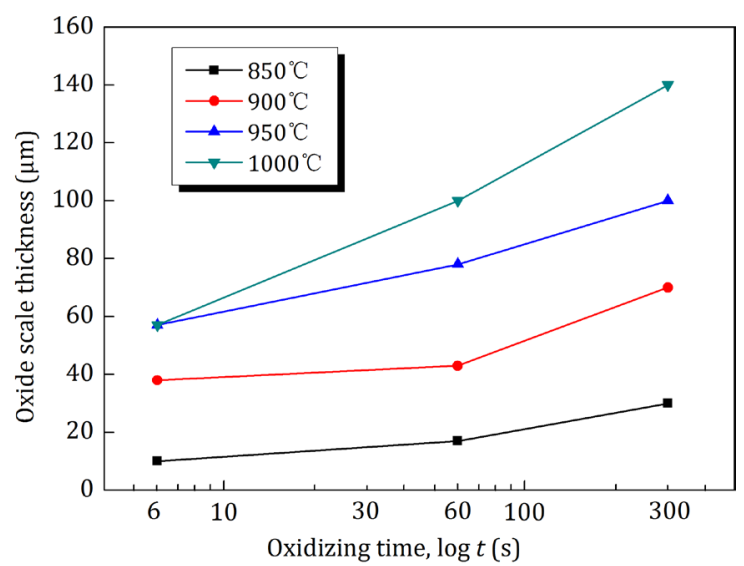

Figure 2. Thickness of oxide scales of steel strip in different heat processes.

by choosing the different holding times for the different heat temperatures. The predefined holding times and thickness of oxide scales for the different heat temperatures are shown in Table 2. The critical thickness of oxide scale before rolling process is the critical points of promotion and inhibition oxide scale of steel strip.

Table 2. Predefined holding times and thickness of oxide scales before rolling process $(\mu \mathrm{m})$

\begin{tabular}{lccccc}
\hline $\begin{array}{l}\text { Holding } \\
\text { times }\end{array}$ & $\mathbf{0 ~ s}$ & $\mathbf{6 ~ s}$ & $\mathbf{6 0} \mathbf{s}$ & $\mathbf{3 0 0} \mathbf{s}$ & $\begin{array}{c}\text { Critical } \\
\text { thickness }\end{array}$ \\
\hline $850{ }^{\circ} \mathrm{C}$ & - & 10 & - & 30 & 20 \\
$900^{\circ} \mathrm{C}$ & 33 & - & 43 & - & 30 \\
$950{ }^{\circ} \mathrm{C}$ & 38 & - & 78 & - & 50 \\
$1000^{\circ} \mathrm{C}$ & & 57 & - & 140 & 70 \\
\hline
\end{tabular}

"-" denotes the holding time is not chosen.

Step II: Adjust roll gap of rolling mill, take the heated steel strip sample from furnace $2 \#$, and carried out the rolling process by one pass. The rolling reduction of one pass is about $5 \%-40 \%$. 
Step III: The rapid cooling was carried out for the rolled steel strip sample to room temperature by spraying water.

Step IV: The red scales of samples are analyzed by the spectrophotometer, and then the pickling experiments were carried out for these samples.

Step V: The step I to step II were repeated for other samples in the same conditions, but in the step III, the hot rolled sample were sprayed immediately glass powder on the surface, and then air cooled to room temperature. The morphology of oxide scales of samples were observed along the cross section by SEM.

\subsubsection{Pickling test}

The hot rolled steel strip samples were detected by spectrophotometer to analyze the extent of red scale. Subsequently, the pickling experiments were carried out on a self-made pickling experiment device. The detailed experimental processes are described as follows.

1. The acid solution (concentration of about $90 \mathrm{~g} / \mathrm{l} \mathrm{HCl}$ and $50 \mathrm{~g} / 1 \mathrm{FeCl}_{2}$ ) was heated in the water bath to $80{ }^{\circ} \mathrm{C}$, and the concentration and the temperature were close to those of the middle pickling tank of the industry pickling line.

2. Adding inhibitors to prevent the formation of bubbles around the samples and over pickling, opening the impeller (rotating at 850rpm) in the acid solution to simulate turbulent flow condition.

3. The different samples were put into the acid solution, and were taken out until the surface oxide scales of samples were removed completely by pickling. The pickling process was recorded by the video. The pickling time is determined by distinguishing the color change of the sample surface.

\subsection{Experimental equipments}

The two heating furnaces were used for the preparation of surface oxide scales of steel strip sample. The heating furnace 1 \# was heated at nitrogen $\left(\mathrm{N}_{2}\right)$ atmosphere, while heating furnace $2 \#$ was at air atmosphere. The glass powder (component $\mathrm{PbO}-\mathrm{B}_{2} \mathrm{O}_{3}-\mathrm{SiO}_{2}$ ) with melting point $450{ }^{\circ} \mathrm{C}$ was used to isolate the air, and avoid the further oxidation of steel strip sample at high temperature. The $38 \% \mathrm{HCl}$ and $\mathrm{FeCl}_{2} \cdot 4 \mathrm{H}_{2} \mathrm{O}$ were used to executing the picking experiments of oxide scales. Spectrophotometer is used to measure the surface red degree $\left(a^{*}\right)^{20}$ to evaluate the tendency of red rust. The morphology of oxide scales of samples were was investigated by SEM (TESCAN VEGA II). The SONY video (HDR-CX450) was used to record the color change during the pickling experiments.

The rolling experiments were carried out by a two-high rolling mill. The dimension of rollers were $\Phi 170 \times 300 \mathrm{~mm}$, the maximum rolling force was about $300 \mathrm{kN}$, and the rolling speed was about $0.2 \mathrm{~m} / \mathrm{s}$.

\section{Results and Discussion}

\subsection{Effect of rolling process on thickness of oxide scales}

It is well known that the implement of rolling process is mainly depends on the contact friction between roller and rolled piece. The rolling process will inevitably affect the oxide scales on the surface of steel sample. Fig. 3 shows the macroscopic morphology of oxide scales of the sample surface under different rolling conditions.

From Fig. 3, it can be seen that the surface oxide scales are mainly manifested as three states, fall off (at the edge or the middle positions), uniformly covering, and surface cracks. By comparing Fig. 3(a) - Fig. 3(d), the thickness of oxide scales are approximately equal based on the data of Table 2. There are obvious edge cracks and oxide scale dropping on the surface of steel samples which have small rolling reduction, as shown in Fig. 3(a) and Fig. 3(c). This is because the temperature at the sample edge dropped faster than the sample middle, and the rolling temperatures of sample edges are lower than others. The oxide scales plasticity has a positive correlation with the temperature ${ }^{21}$. The lower temperature at sample edge increase the surface crack tendency and dropping tendency of the oxide scales.

By comparing Fig. 3(a) with Fig. 3(b), Fig. 3(c) with Fig. 3(d), the crack and dropping of oxide scales can be inhibited with increasing of rolling deformation. It is also evident proof to confirm the effect of rolling reduction to oxide scales from Fig. 3(d), (h), and (1). This is because large rolling reduction cause the thinning of oxide scales thickness and strengthen the adhesion of oxide scales with substrate, which enhancing the ability of resisting cooling shrinkage of oxide scale after rolling. Therefore, the oxide scale is not easy to crack or fall off.

The thickness of oxide scales has an important impact on the morphology of oxide scales undergoing rolling and cooling process. The cracks of oxide scales at high temperatures $\left(950^{\circ} \mathrm{C}\right.$ and $\left.1000^{\circ} \mathrm{C}\right)$ are more severe than low temperatures $\left(850^{\circ} \mathrm{C}\right.$ and $\left.900^{\circ} \mathrm{C}\right)$. The thicknesses of oxide scales at high temperatures are thicker than at low temperatures. This view is inaccurate. This sentence and subsequent should be described like this: The thicker oxide scale, the larger interior shrinkage stress for thicker oxide scale during water cooling process, therefore, the cracks of surface oxide scales are easy to occur at high temperature. Therefore, the cracks of surface oxide scales are easy to occur at high temperature. In addition, the larger interior shrinkage stress for thicker oxide scale also causes the more cracks during water cooling process.

Therefore, the morphology of oxide scales of steel strip samples is closely related to the rolling temperature, rolling reduction and the thickness oxide scale. Table 3 shows the influence of rolling parameters on the traits of oxide scales, which can be used to explain the surface morphology 

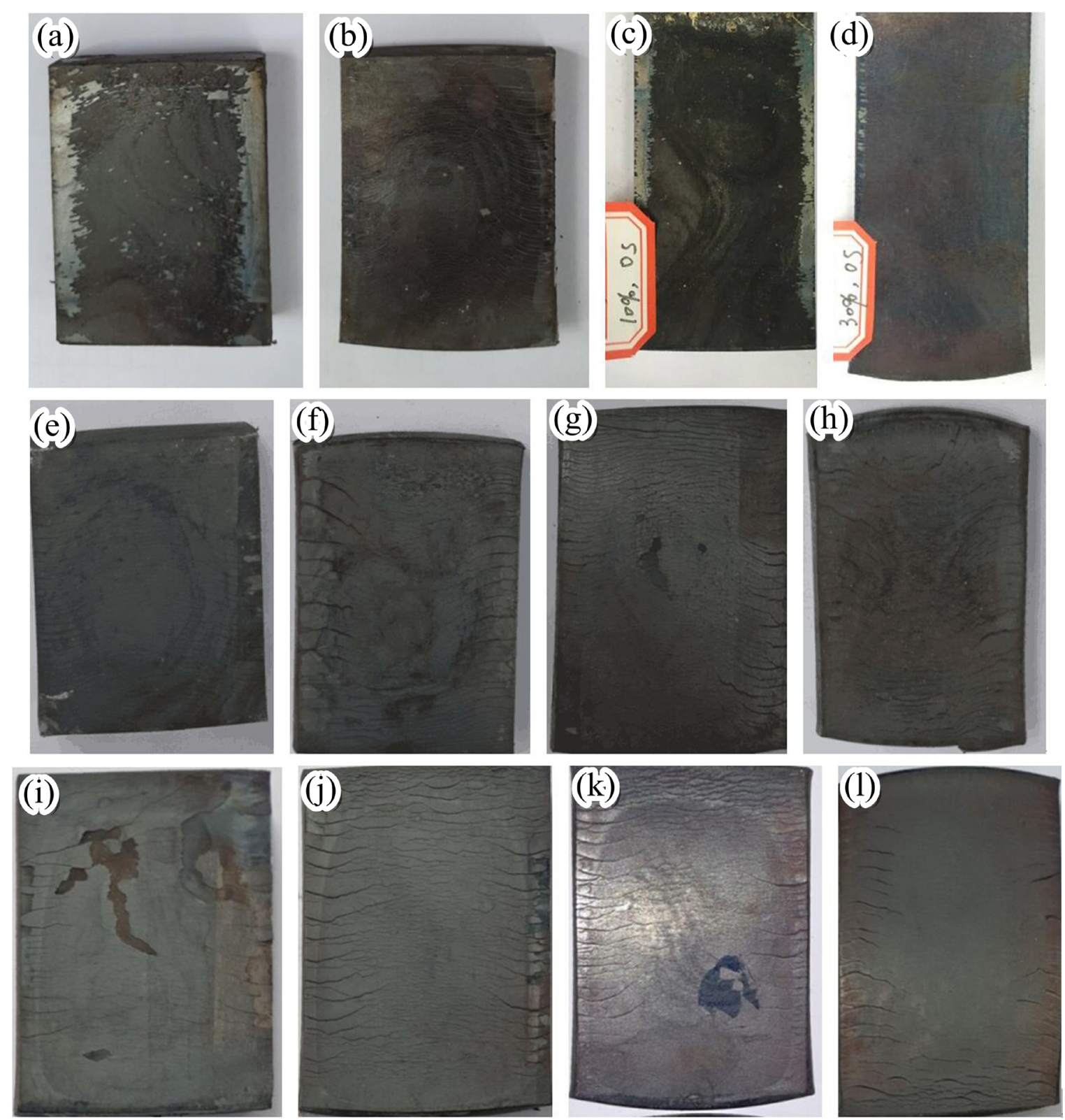

Figure 3. Surface morphology of oxide scale of samples after rolling. (a) $850{ }^{\circ} \mathrm{C}-300 \mathrm{~s}-5 \%$; (b) $850{ }^{\circ} \mathrm{C}-300 \mathrm{~s}-20 \%$; (c) $900{ }^{\circ} \mathrm{C}-0 \mathrm{~s}-10 \%$; (d) $900^{\circ} \mathrm{C}-0 \mathrm{~s}-30 \%$. (e) $950^{\circ} \mathrm{C}-60 \mathrm{~s}-10 \%$; (f) $950{ }^{\circ} \mathrm{C}-60 \mathrm{~s}-20 \%$; (g) $950^{\circ} \mathrm{C}-60 \mathrm{~s}-30 \%$; (h) $950{ }^{\circ} \mathrm{C}-60 \mathrm{~s}-40 \%$. (i) $1000^{\circ} \mathrm{C}-6 \mathrm{~s}-10 \%$; (j) $1000{ }^{\circ} \mathrm{C}-6 \mathrm{~s}-$ $20 \%$; (k) $1000^{\circ} \mathrm{C}-6 \mathrm{~s}-30 \%$; (1) $1000^{\circ} \mathrm{C}-6 \mathrm{~s}-40 \%$

Table 3. The influence of rolling parameters on the traits of oxide scales

\begin{tabular}{|c|c|c|c|c|c|c|}
\hline \multirow[t]{2}{*}{ Traits of oxide scale } & \multicolumn{2}{|c|}{$\begin{array}{l}\text { Rolling temperature (influence } \\
\text { oxide scale plasticity) }\end{array}$} & \multicolumn{2}{|c|}{$\begin{array}{l}\text { Rolling reduction (influence } \\
\text { degree of oxide scale } \\
\text { self-compacting and pressing } \\
\text { into substrate) }\end{array}$} & \multicolumn{2}{|c|}{$\begin{array}{l}\text { Oxide scale thickness before } \\
\text { rolling (influence oxide scale } \\
\text { plasticity and self-compacting) }\end{array}$} \\
\hline & high & low & large & small & thick & thin \\
\hline $\begin{array}{l}\text { Crack tendency (correlate } \\
\text { with oxide scale plasticity) }\end{array}$ & $\downarrow$ & $\uparrow$ & $\uparrow$ & $\downarrow$ & $\uparrow$ & $\downarrow$ \\
\hline $\begin{array}{l}\text { Dropping tendency } \\
\text { (correlate with oxide scale } \\
\text { adhesion to substrate) }\end{array}$ & $\downarrow$ & $\uparrow$ & $\downarrow$ & $\uparrow$ & $\uparrow$ & $\downarrow$ \\
\hline
\end{tabular}


comprehensively. Generally, the morphology of oxide scale is determined collectively by several of influence factors, and dominated by one of factors in a certain condition.

\subsection{Effect of rolling process on thickness of oxide scale}

The oxide scales will be elongated or fractured during the rolling process of steel strip. The rolling process has an important impact on the oxide scales on surface of steel strip. The cross section thicknesses of oxide scale for typical rolling process are shown in Fig. 4.The thickness of oxide scale increase with the increase of temperature. The glass powder is immediately sprayed on the surface of sample after the steel strip is rolled. The air is isolated from the surface of steel sample due to the melt of glass powder. The state of oxide scales at high temperature is preserved without further oxidizing during subsequently cooling. Therefore, the thickness of oxide scale is the real thickness of steel strip undergoing rolling at high temperature, it is mainly affected on the rolling process and the pre-rolled thickness of oxide scales. In Fig.4, it can be seen that the oxide scales have certain plasticity on high temperature. The crack of oxide scale increase with the increase of rolling reduction.

For the different rolling conditions, the thicknesses of oxide scales of rolled steel strips were measured based on the above-mentioned SEM images, as shown in Fig. 5.

From Fig. 5, it can be seen that the thickness of rolled oxide scale increases with the increase of pre-rolled oxide scale thickness, and decreases with the increase of the rolling reduction. For the same rolling temperature, the thicknesses of oxide scale thicken with the increase of heating time. In addition, the deformation capacity of oxide scale is improved with the increase of temperature. The oxide scale thicknesses of steel strips are thinned with the increase of the rolling reduction. It shows that the oxide scales have certain plasticity at high temperature ${ }^{5,22,23}$.

In order to investigate the effect of oxide scales on the pickling time, the pickling experiment were carried out on a self-made pickling experiment device. The pickling times for different rolling conditions are shown in Fig. 6.

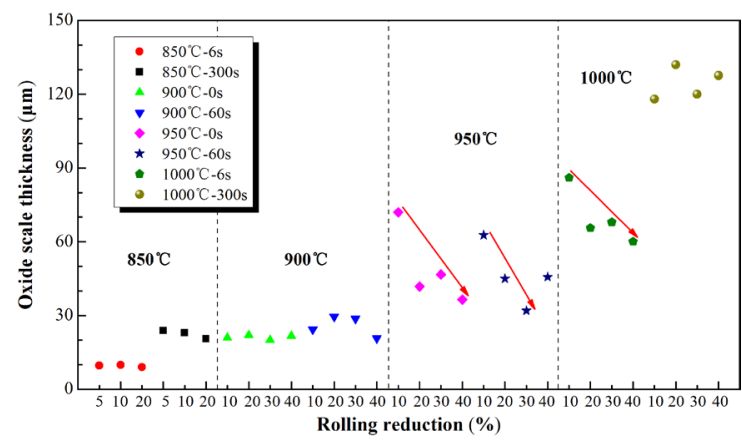

Figure 5. The relationship of the thickness of oxide scale and rolling conditions.

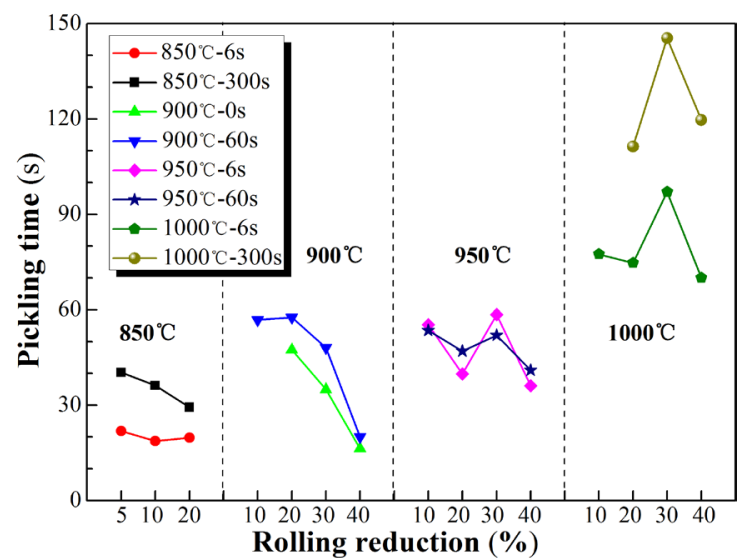

Figure 6. The pickling time of steel strip samples in different rolling conditions.

From Fig. 5 and Fig. 6, it can be seen that the pickling time is strongly depend on the thickness of oxide scales of steel strip samples. The pickling time increases with the increase of rolling temperature and the prolongation of holding time at high temperature, essentially because the oxide scale thickness increase. The pickling time was reduced with the increase of rolling reduction at the same temperature. The reason is that the thickness of oxide scale becomes to be thin with the increase of rolling reduction.
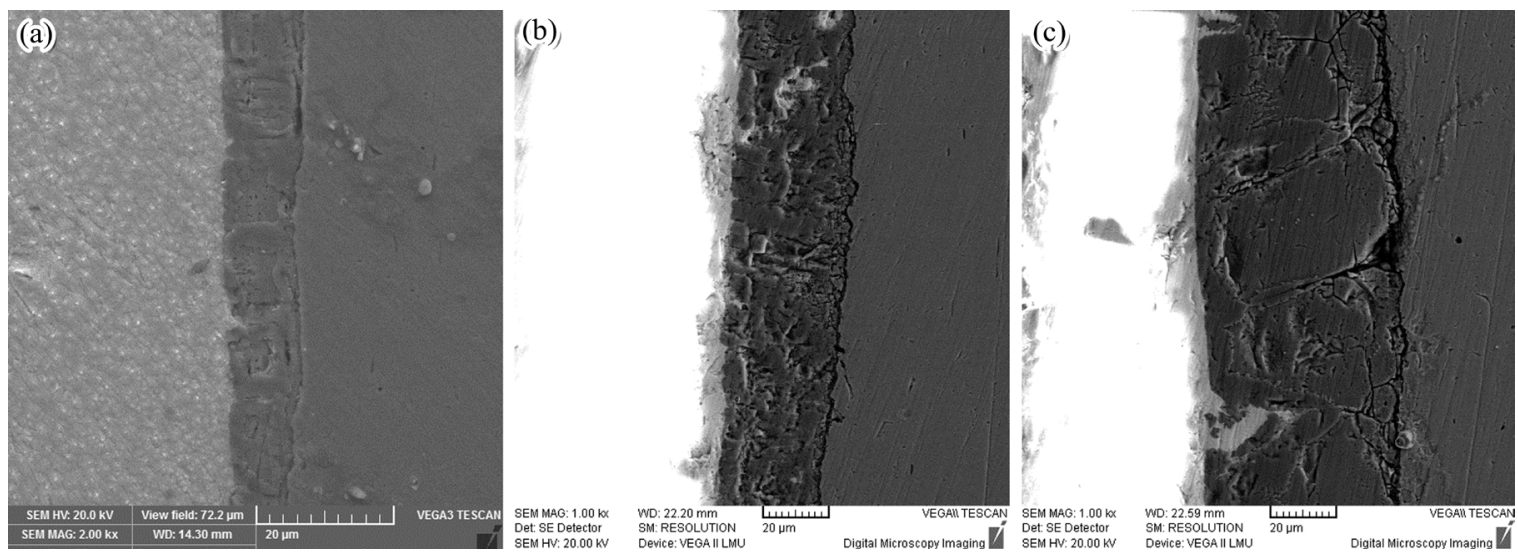

Figure 4. SEM of cross section oxide scale of rolled samples. (a) $850^{\circ} \mathrm{C}-6 \mathrm{~s}-20 \%$; (b) $950^{\circ} \mathrm{C}-60 \mathrm{~s}-30 \%$; (c) $1000^{\circ} \mathrm{C}-6 \mathrm{~s}-40 \%$. 
In Fig. 6, it is worth noting that the variation of pickling time is not consistent with the thickness variation of oxide scale, and appears rebounding and even peak value with $30 \%$ rolling reduction at $1000^{\circ} \mathrm{C}$. The thickness of oxide scale in this condition is no thicker than other rolling conditions. Therefore, there are other factors affect the pickling time except the thickness of oxide scale. The rolled steel strip samples were rapidly cooled to the room temperature by spraying water. The eutectoid transformation of $\mathrm{FeO}$ was inhibited. Therefore, the oxide scales of pickling samples are composed by a large amount of $\mathrm{FeO}$ and small amount of $\mathrm{Fe}_{3} \mathrm{O}_{4}$ and $\mathrm{Fe}_{2} \mathrm{O}_{3}$. In this case, the component of oxide scales is not the main reason for the change of pickling time in $30 \%$ rolling reduction.

Another factor influencing the pickling time is the surface morphology of the hot rolled steel strip sample. Comparing Fig. 3(i)-(1), the surface crack of oxide scale in 30\% rolling reduction is finer than one of $20 \%$. The distance of adjacent cracks in $30 \%$ rolling reduction is smaller than others. This indicates that the originally porous $\mathrm{FeO}$ was pressed more compact due to the large rolling deformation, and result in enhancing water cooling shrinkage resistance. The compact oxide scale is able to inhibit the permeation capacity of acid solution ${ }^{24}$. This is one of the reasons for the variation of pickling time.

The rolling deformation has important impacts on the thickness of oxide scales and its compactness, and then indirectly affects the pickling time of hot rolled steel strip. The schematic diagram of the effects of rolling deformation on the pickling process is shown in Fig. 7. With the increase of rolling reduction, the thickness of oxide scale is decrease, and the compactness of oxide scale is increase. The thickness and compactness of oxide scale have the opposite effects on the pickling process. The combined effect of two factors results in appearing peak value of pickling time for the hot rolled sample in $30 \%$ rolling reduction.

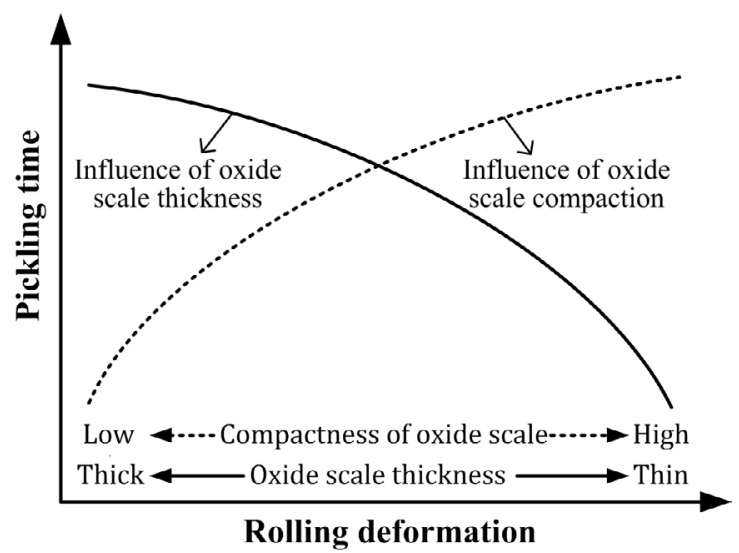

Figure 7. Schematic diagram of the effects of rolling deformation on the pickling time.

\subsection{Effect of rolling process on surface red scales}

The surface red degree of the steel strip samples rolled by various rolling conditions is measured by the spectrophotometer, and the results are shown in Fig. 8. If $a^{*}>1.5^{20}$, it is considered to surface color become reddish and red scale easily appear. From the point of view of inhibiting the formation of red scale, the overall trend is that the higher rolling temperature is, the greater the allowable critical deformation to inhibit red scale become; the higher the rolling temperature is, the thicker tolerable thickness of the initial oxide scale is. Thus, it can be extended to hot strip rolling process, according to the variation principle of the rolling temperature decreasing gradually, should try to improve properly the load distribution of head frames, reduce the deformation of tail frames rolling, and that is conducive to inhibit strip red scale.

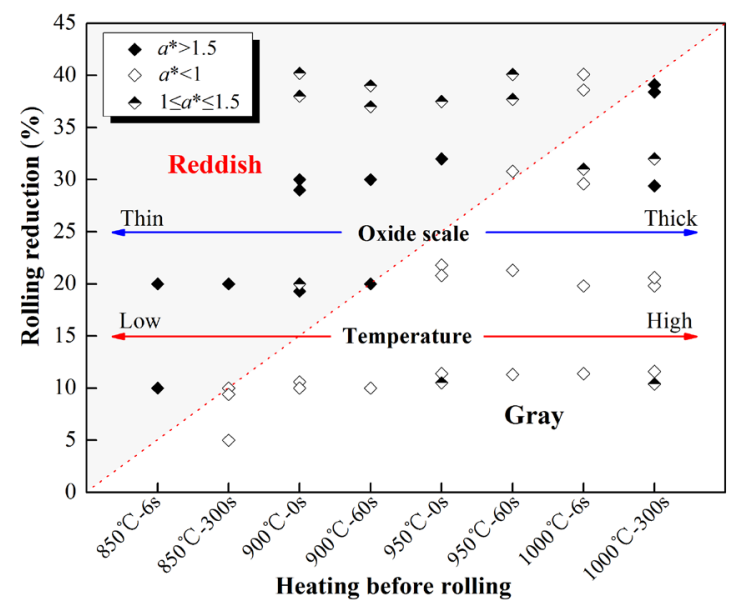

Figure 8. The relationship between rolling conditions and surface red degree value $a^{*}$.

\section{Conclusions}

1. The oxide scale has a certain extent of plasticity at high temperature. In the same experimental conditions, the greater the rolling deformation is, the thinner of the oxide scale spread. The plasticity of the oxide scale enhances with the increase of rolling temperature. The oxide scale can be compacted under a larger rolling reduction, which increase the adhesion of oxide scale to steel substrate and reduce the trend for falling off.

2. The rolling process has an important impact on the red scale on the surface of steel strip. The higher rolling temperature is, the greater the allowable critical deformation to inhibit red scale is, and the thicker tolerable thickness of the initial oxide scale is. 
3. In hot steel strip rolling process, increase the rolling loads distribution in the front rolling stands and reduce the rolling deformation in the last few rolling stands are effective measures to inhibit surface red scales.

4. The thickness and compactness of oxide scale have the opposite effects on the pickling process of steel strip. The pickling time is longest in $30 \%$ rolling reduction.

\section{Acknowledgment}

This work was financially supported by the National Natural Science Foundation of China (51421001).

\section{References}

1. Wu HB, Wang D, Zhang PC, et al. Influences of alloying elements on oxidation behavior of steels and microstructure of oxide scales. Journal of Iron and Steel Research, International. 2016;23(3):231-237.

2. Wang C, Yu Y, Wang L, Pang ZG, Chen J, Jiao HL. Effects of $\mathrm{C}$ and $\mathrm{P}$ on blistering behavior of scale of hot rolled strip. Journal of Iron Steel Research. 2016;28(3):74-79.

3. Yu Y, Wang C, Wang L, et al. Combination effect of Si and P on tertiary scale characteristic of hot rolled strip. Journal of Iron and Steel Research, International. 2015;22(3):232-237.

4. Fukagawa T, Okada H, Maehara Y. Mechanism of red scale defect formation in Si-added hot-rolled steel sheets. ISIJ International. 1994;34(11):906-911.

5. Takeda M, Onishi T, Nakakubo S, Fujimoto S. Physical properties of iron-oxide scales on Si-containing steels at high temperature. Materials Transactions. 2009;50(9):2242-2246.

6. Liu XJ, He YQ, Cao GM, et al. Effect of Si content and temperature on oxidation resistance of Fe-Si alloys. Journal of Iron and Steel Research, International. 2015;22(3):238-244.

7. Zuo J, Chang J, Liu Y, Zhang KH, Yang JC, Li WP. Formation mechanism and improvement measures of red rust iron oxide skin of hot-rolled steel plate. Iron \& Steel. 2010;45(10):84-87.

8. Wang C, Yu Y, Pan H, Wang L, Chen J, Xu HW. Influencing factors and formation mechanism of banded red scale defect on hot rolled high strength steel strip surface for mechanical engineering application. Iron \& Steel. 2014;49(9):64-70.

9. Dong XX, Tang Q. Scale formation causes of hot rolled SPHC strip and its control measure. Steel Rolling. 2011;28(5):56-58. DOI:10.13228/j.boyuan.issn1003-9996.2011.05.019 http:// en.cnki.com.cn/Article_en/CJFDTOTAL-ZZGG201105022.htm
10. Wang YJ, Mu HL, Dong HJ, Li XB, Zhang GH, et al. Cause analysis of difficult pickling of oxide scale of SPHC hot-rolled strip and its countermeasures. Steel Rolling. 2006;23(4):51-54.

11. Sun JQ, Zhang F. Formation of oxidizing defect on the surface of strip and preventive measures. Angang Technology. 2013;(2):1-5.

12. Kato O, Yamamoto H, Ataka M, Nakajima K. Mechanisms of surface deterioration of roll for hot strip rolling. ISIJ International. 1992;32(11):1216-1220.

13. Hui YJ, Li WY, Zhao AM, Cai AY, Zhao ZZ, Yin HX. Study on the morphology and oxidation kinetics of oxide scale of hot rolling strip steel. Journal of Iron Steel Research. 2013;25(4):54-58.

14. Tominaga J, Wakimoto KY, Mori T, Murakami M, Yoshimura T. Manufacture of wire rods with good descaling property. Transactions of the Iron \& Steel Institute of Japan. 1982;22(8):646-656.

15. Bhattacharya $R$, Jha $G, K$ Kundu $S$, et al. Influence of cooling rate on the structure and formation of oxide scale in low carbon steel wire rods during hot rolling. Surface \& Coatings Technology. 2006;201(3-4):526-532.

16. Zhang M, Shao G. Characterization and properties of oxide scales on hot-rolled strips. Materials Science and Engineering: A. 2007;452:189-193.

17. Cao GM, Wu TZ, Xu R, et al. Effects of coiling temperature and cooling condition on transformation behavior of tertiary oxide scale. Journal of Iron and Steel Research, International. 2015;22(10):892-896.

18. Liu ZY, Yu Y, Guo XB, Guan J, Wang GD. Techniques of oxide scales control during hot strip rolling. Steel Rolling. 2009;26(1):5-9.

19. Utsunomiya H, Doi S, Hara KI, Sakai T, Yanagi S. Deformation of oxide scale on steel surface during hot rolling. CIRP Annals - Manufacturing Technology. 2009;58(1):271-274.

20. Okada H, Fukagawa T, Ishihara H, Okamoto A, Azuma M, Matsuda Y. Prevention of red scale formation during hot rolling of steels. ISIJ International. 1995;35(7):886-891.

21. Suárez L, Houbaert Y, Eynde XV, Cólas R. High temperature deformation of oxide scale. Corrosion Science. 2009;51(2):309315 .

22. Hara K, Utsunomiya H, Sakai T, Yanagi S. Oxide scale behavior and rolling characteristics in hot steel rolling. Tetsu-to-Hagane. 2011;97(7):393-398

23. Sun W, Tieu A K, Jiang Z, et al. High temperature oxide scale characteristics of low carbon steel in hot rolling. Journal of Materials Processing Technology. 2004;155-156(1):1307-1312.

24. Dong HJ, Wang YJ. Factors Influencing pickling quality and speed of oxide scale on hot rolled strip. Materials for Mechanical Engineering. 2009;33(3):83-89. 